\title{
A Study on the Authenticity of Ethnic Tourism from the Perspective of Community Residents - - Taking Jiu Zhaigou Song and Dance Performance as an Example
}

\author{
Ping Fang \\ School of Management, Shanghai University, Shanghai, China \\ Email: fp13813137729@126.com
}

\begin{abstract}
Tourism has developed very fast in China past decades and experts all over the world pay close attention to the research about "authenticity" of folk activities. Taking Jiu Zhaigou Song and Dance Perfomance as an example, this paper explores the authenticity of Jiu Zhaigou Song and Dance Performance from the perspective of tourism sociology, and explores tourists' perception of the authenticity of Jiu Zhaigou Song and Dance Performance from the perspective of local residents.
\end{abstract}

Keywords: Ethnic travel, authenticity, Jiu Zhaigou, song and dance performance

\section{Introduction}

The concept of authenticity originates from the Greek word "authents", which means primitive, original and self-made. Later, the word "authenticity" developed into "authenticity". Authenticity has the meaning of "original" and "creator". It was originally used in museums to describe the authenticity of art exhibits. ${ }^{[1]}$ It was Boorstin who first applied the concept of "authenticity" to tourism. He published The Image: A Guide to Pesudo-events, in which Boorstin first exposed some "false events" in tourism. Mac Cannell, through the article Staged Authenticity, applied the concept of authenticity to tourism research more deeply, and then caused the research and application of tourism authenticity in academic circles. ${ }^{\left[{ }^{2]}\right.}$

At present, the concept of tourism authenticity in academic circles has four main schools: objective authenticity, constructive authenticity, existential authenticity and post-modern authenticity. The objective authenticity focuses on the tourist object, and authenticity is an inherent attribute with absolutely measurable criteria to judge its authenticity; unlike objective authenticity, which gives the right to determine authenticity to tourists, constructivism holds that the "authenticity" of the object can also be shaped, and that each person's travel needs and experience are different. Different, so this authenticity is relative, some things initially considered untrue will become a kind of "new reality" with the passage of time; scholars who agree with post-modern authenticism think that people no longer care about the authenticity of the original works, and this view stems from post-modernism trend of thought; Wang Ning believes that the authenticity of the original works is no longer concerned. For the authenticity of existence has nothing to do with the authenticity of the tourist object itself, but tourists use tourism activities or tourist objects to find their true selves. He divides the authenticity of existence into the authenticity within and between individuals. ${ }^{[3]}$

In the field of foreign tourism, Trilling (1972) believes that the concept of authenticity implies controversy; Geary (1986) believes that the two elements of authenticity are miracles and attract a large number of pilgrims; Handler\&Saxton (1988) first separates the subject and object from reality and proposes tangible items. And the experience of performing arts is real; Bruner (1994) summarizes the four connotations of tourism authenticity; Colomb (1995) believes that the understanding of Authenticity's concept depends on the context or level of its application; Taylor (2001) distinguishes the type of authenticity. Depending on how many people are on authenticity; Reisinger and Steigner (2006) emphasize that authenticity cannot be used as a basic concept because it cannot be unanimously recognized by subject members; Cohen (2007) has six meanings of authenticity; domestic tourism The understanding of authenticity is different: Zhang Jiangang (1995) translated Singer's works discussed the authenticity standards of art historians, collectors, and businessmen; Zhang Xiaoping (2003) introduced Mac Cannell's stage theory of truth ${ }^{[4]}$; Li Xudong (2005) Ethnic tourism as an example to explore three theories of authenticity; Xie Yanjun (2006) believe that most scholars understand the truth depends on intuition. 
Since the current academic community does not have a unified definition of the concept of authenticity, the author combines "construction of authenticity" and "existence of authenticity" in this study to look at the issue of tourism authenticity, that is, tourism is a tourist borrowing a tour to seek the self. In the process, they completely abandon the tourist object, do not pursue their true and false, emphasize the subject to experience the state of self-existence, that is, pay more attention to their own experience. ${ }^{[5]}$

\section{Interpretation of the Authenticity of Jiu Zhaigou Song and Dance Performance}

\subsection{Overview of Jiu Zhaigou Ethnic Performing Songs and Dances}

Jiu Zhaigou Scenic Area is located in the northwest of Aba Tibetan and Qiang Autonomous Prefecture, Sichuan Province, China. It is also the second largest Tibetan area and the largest famous world natural heritage tourist destination in Qiang area. The production of Jiu Zhaigou folk song and dance performance is accompanied by the development of Jiu Zhaigou tourism.

Since the formal development of tourism in 1984, in order to improve the competitiveness of tourism, some hotel owners have begun to plan entertainment activities for tourists at night, including Tibetan and Qiang singing and dancing performances. These performers who perform songs and dances for tourists are mainly temporary waiters in hotels and hotels, mostly Tibetans or Qiang people.

In 1994, Jiu Zhaigou National Art Troupe, the first officially registered and foreign business performing group, was established. From the very beginning, the group has designed cultural content according to the principle of "attracting more tourists and making them happy". Its main purpose is to gain more commercial profits and give consideration to the dissemination and display of Tibetan and Qiang culture.

In 1998, in order to protect the ecological environment of scenic spots, with the implementation of the government's policy of "living outside ditches and traveling inside ditches", all accommodation and catering were transferred to Zhangzha Town Street outside ditches. With the increasing number of tourists in Jiu Zhaigou, more and more foreign investors have increased their use of Tibetan and Qiang culture to attract tourists by singing and dancing performances and achieve the goal of maximizing economic benefits. Apart from the "Tibetan fans" art troupe, the other seven art troupes in Jiu Zhaigou are mainly to show Tibetan and Qiang cultures. The focus of marketing to tourists is the authenticity of the performing culture, that is, the authentic marketing in the tourism market.

\subsection{Ethnic Song and Dance Performance and Tourism Authenticity in Jiu Zhaigou}

From the perspective of the emergence and development of Jiu Zhaigou ethnic singing and dancing performances, these performances mainly transfer the Tibetan and Qiang cultural symbols from other areas outside Jiu Zhaigou to Jiu Zhaigou, with the "authenticity" of Tibetan and Qiang culture as the selling point, and become a typical product of tourism authenticity under the common construction of the society. Their performances are as follows:

Firstly, from the point of view of the investment subjects of the troupe, there are individuals and units, including local administrative departments, investors in different industries, some large catering and cultural enterprises and Tourism Management organizations, as well as a few famous Tibetan singers and modern pop music professionals.

Secondly, from the perspective of performance form, in order to please the public tourists, most art troupes adopt the form of singing and dancing party with strong entertainment and appreciation. Its content and form are much more beautified and exaggerated than daily life, and its packaging is very meaningful.

Thirdly, from the point of view of performance purpose, it is mainly to solve the problem of "playing in the daytime ditch and having nowhere to play at night" of tourists in Jiu Zhaigou. It is the result of the commercialization of Tibetan and Qiang culture and the "authenticity" of Tibetan and Qiang culture deliberately created by tourist destinations with Tibetan and Qiang traditional culture as raw material, which is related to the original Tibetan and Qiang culture. The functions of self-entertainment and self-enjoyment of culture differ greatly. The Tibetan and Qiang culture experienced by tourists is not the culture of the Tibetan and Qiang native areas, but a culture designed and conceived by some subjects. 


\section{$3 \quad$ Empirical Analysis of Local Residents' Truth Perception}

Researchers first show pre-recorded singing and dancing performances, and then conduct a survey. The contents include the content of songs, melody, dance content, dance movements, posture and other items related to the authenticity of singing and dancing itself in Jiu Zhaigou folk singing and dancing performances, as well as other performance factors affecting authenticity judgement, such as performers, performance organization forms, organizers, performance time and location.

A total of 121 valid questionnaires were collected, including 50 males and 71 females. The age limit of the respondents is over 18 years old. The group over 18 years old can have their own opinions on the authenticity. The age group is divided into the youth group, the middle-aged group and the elderly group, and the sample is counted (Table 1).

Table1. Samples of Jiu Zhaigou tourist survey

\begin{tabular}{ccccc}
\hline Age group & 18-30year & 31-55year & Age 56 and above & Total \\
\hline Sample size & 38 & 62 & 21 & 121 \\
male & 20 & 20 & 10 & 50 \\
female & 18 & 42 & 11 & 71 \\
\hline
\end{tabular}

Male accounted for $41.3 \%$ of the total, female $58.7 \%$, young people aged $18-30$ accounted for $31.4 \%$, middle-aged people aged 31-55 accounted for $51.3 \%$, and elderly people over 56 accounted for $17.3 \%$. The authenticity of singing and dancing itself and other performance factors affecting authenticity cognition were investigated through the questionnaire of Lickett Scale 5, and the results were analyzed by means of the questionnaire.

Table 2. Mean value analysis of local residents' evaluation of the authenticity of song and dance performance in Jiu Zhaigou

\begin{tabular}{c|cccc|ccccc}
\hline & \multicolumn{4}{|c|}{$\begin{array}{c}\text { The authenticity of the song and dance } \\
\text { itself }\end{array}$} & \multicolumn{4}{c}{ Other factors that affect perception of authenticity } \\
\cline { 2 - 11 } & $\begin{array}{c}\text { Musical } \\
\text { content }\end{array}$ & $\begin{array}{c}\text { Song } \\
\text { melody }\end{array}$ & $\begin{array}{c}\text { Content of } \\
\text { the dance }\end{array}$ & $\begin{array}{c}\text { Dance } \\
\text { moves }\end{array}$ & $\begin{array}{c}\text { Performance } \\
\text { personnel }\end{array}$ & $\begin{array}{c}\text { Show } \\
\text { time }\end{array}$ & $\begin{array}{c}\text { Performance } \\
\text { place }\end{array}$ & $\begin{array}{c}\text { Show } \\
\text { organizer }\end{array}$ & $\begin{array}{c}\text { Performance } \\
\text { organization }\end{array}$ \\
\hline Youth & 4.2 & 3.8 & 4.1 & 3.6 & 2.9 & 4.6 & 3.6 & 3.7 & 3.0 \\
\hline $\begin{array}{c}\text { Middle-aged } \\
\text { group }\end{array}$ & 3.8 & 3.3 & 3.2 & 3.1 & 2.5 & 3.9 & 3.2 & 3.3 & 2.4 \\
\hline Elderly group & 2.9 & 2.8 & 1.7 & 2.2 & 1.5 & 2.6 & 2.5 & 2.5 & 1.4 \\
\hline
\end{tabular}

According to the data in the table, there is a huge difference between local residents' cognition of the authenticity of song and dance performances and other performance factors. The average value of cognition of the authenticity of song and dance is generally higher than that of other factors that affect the authenticity of cognition. Generally speaking, residents have certain identification with the authenticity of the song and dance performances, especially the song and dance movements and gestures, which are mostly considered to be real and relatively real. On the contrary, residents have basically different attitudes towards the authenticity of other performance elements, such as performers, organizational forms and locations.

There are huge age differences in the content of the performances themselves. Young people and old people are at both ends of this difference, while middle-aged people are in between, but tend to be young people. Young people's answers to different questions were all higher than those of middle-aged and elderly people, who had the lowest mean among the three groups. Young and middle-aged people mostly believe that the content of singing and dancing is real and relatively real, while the elderly hold the opposite attitude. 


\section{$4 \quad$ Authentic Interview Analysis of Local Residents}

We conducted face-to-face interviews with local residents to get a deeper and more specific understanding of their views on the authenticity of performances. Interviews with local tour operators, local song and dance performers and home-based residents revealed that most of their answers focused on the following points:

Table 3. Summary of interviews with local residents

\begin{tabular}{ll}
\hline Type of Residents & Content of Interview \\
\hline Local Tour Operator & 1. The performances are Tibetan songs and dances, but more exaggerated \\
& 2. The costumes of the show are too gorgeous to be normally worn \\
& 3. The performances are directed by professionals hired from outside \\
& 4. As long as tourists are happy \\
& 5.We can make money by buying tourist products, we don't want to show Tibetan culture \\
& 1. I like singing and dancing, so I stayed to be an actor.; \\
& 2. I can earn money through acting; \\
Local Performer & the surferent from the real song and dance performances in Jiu Zhaigou, Tibetan elements in \\
& 4. As long as the tourists are happy, it is real \\
1. They attract tourists with singing and dancing performances, resulting in almost no & tourism income for us. \\
2. They get the benefit, we don't get the benefit, it has nothing to do with us, \\
3. Singing and dancing mainly for money, with little authenticity \\
4. Those on the stage are made of tourists' curiosity and ignorance of Tibetan things
\end{tabular}

Through the interviews after the survey, it can be found that the cognition of the authenticity of local residents' tourism singing and dancing performances is mainly based on two aspects: one is the organizers and participants of the performances; Second, the cultural content of performance. These two aspects are actually responses to economic interests and cultural attitudes. Residents in Jiu Zhaigou do not pay much attention to the "authenticity" of singing and dancing. Residents who participate in the jiuzaigou dance show believe that it can bring him profits and make tourists happy, so he thinks it is more real. For the residents who did not participate in the song and dance performances, they did not benefit from them, and as native tibetans, from their point of view, they thought the song and dance performances were not in line with their real life. ${ }^{[6]}$

\section{Conclusion}

\section{1 "Outsiders" in Song and Dance}

Generally speaking, the current residents of Jiu Zhaigou regard themselves as "outsiders" of song-and-dance performances, which is an important reason that they do not get any benefit from song-and-dance performances. This "outsider" status directly affects the residents' judgment of the authenticity of performances, which is firstly reflected in their concern about the authenticity of singing and dancing performances, and secondly, their loss of economic interests also directly affects their judgment of the authenticity of performances.

In the eyes of Jiu Zhaigou residents, because of their "host" status, they should first meet their needs in the distribution of tourism benefits, or they should receive more economic benefits than residents outside the valley. Because there is no "them" Jiu Zhaigou, there is no such tourism benefits. However, due to the need of ecological protection, the business scope of residents in the ditch is limited, and their "economic advantage" has not been fully reflected. On the contrary, those "non-Jiu Zhaigou people" outside the valley use the brand of Jiu Zhaigou to earn more economic benefits, which makes many residents who have benefited from it psychologically unacceptable. ${ }^{[7]}$ 


\subsection{Residents of Jiu Zhaigou Pay Attention to the Authenticity of Dance Performances}

Generally speaking, the residents of Jiu Zhaigou do not care much about these dance performances, and almost no one pays too much attention to the authenticity of these performances. Their attitude focuses on two aspects: one is basically irrelevant to themselves; The second is that they do not seem to be the ones they are thinking about at the moment. The first attitude can be explained by the way the song and dance performances are organized. These singing and dancing performances are organized by tourism enterprises, who make use of the background of Jiu Zhaigou in their publicity and performance. From the perspective of the local community of Jiu Zhaigou, these tourism enterprises have no direct interest in the local residents. At present, the main economic source of the local residents is the commission of the income of the scenic spot and the profit from the sale of tourist commodities.

They are, as Mr Goffman puts it, "outsiders" with little connection to either front or back office. Due to the lack of interest relations, local residents lack the basic motivation to pay attention to the authenticity of the song and dance performances. This is very different from before the closure of family hotels in ditches. Before 2001, the family hotel industry in gully was flourishing, and the singing and dancing performances organized by residents in gully for business needs formed a competitive relationship with the performances outside gully. In order to gain a competitive advantage, performances in the gully need to convey the information of "local characteristics of Jiu Zhaigou" to tourists, and emphasize the "authenticity of the local area" to gain the recognition of tourists. However, with the banning of family hotels and the changes of local residents' economic income channels, the relationship between song and dance performances and the residents in the ditch disintegrated, and it faded out of the view of the residents in the ditch

\subsection{The Aged Group is the Carrier of Traditional Culture}

In the survey of the elderly group, they found that singing and dancing performance is not true, and this kind of unreal is all round, involving dance, song, dress and custom performance and other aspects. There are two main reasons: first, the elderly have a poor ability to adapt to the commodity economy of Jiu Zhaigou, has been separated from the material production. Their economic status in the family is very low and they no longer interfere in the family life. Secondly, due to age, culture and habits, the elderly are not able to adapt to tourism life. The elderly live far away from the tourist activity area, which can be said to be the only "backstage" area in Jiu Zhaigou. They live in the old houses and continue the traditional way of life that they are familiar with. Although they are no longer engaged in material production, they wear Tibetan clothes, sing folk songs and eat Tibetan food, which is an important carrier of traditional culture in Jiu Zhaigou. Therefore, their judgment of folk songs and dances is still largely based on the original Jiu Zhaigou regional cultural tradition.

\section{$6 \quad$ Suggestions}

\subsection{Improve the Participation of Local People in Jiuzhaigou Song and Dance Performances}

From the interview survey of local people, local people did not participate in the activities of Jiuzhaigou song and dance performances in large numbers. The residents of the tourist areas have a higher level of understanding of local folk customs and culture than ordinary actors, if they are in the song and dance performances. When the locals come to perform, they will improve the participation and emotional interpretation of the actors, thus enhancing the recognition and satisfaction of the tourists on the authentic national song and dance performances.

\subsection{The Overall Scene Atmosphere of the Event Should Be More Coordinated}

Under the current national cultural tourism development boom, tourism developers need to pay more attention to how to develop tourism products with rich cultural connotations and high authenticity. The scene of the event stage should pay more attention to the potential environment, such as music, connotation, management, etc., so that the atmosphere of the whole scene is more harmonious, which is beneficial to the tourists to integrate into the whole activity more quickly. 


\section{Reference}

1. Olsen K. Authenticity as a concept in tourism research: The social organization of the experience of authenticity[J]. Tourist studies, 2002, 2(2): 159-182.

2. Peterson A R. In search of authenticity[J].Journal of Management Studies,2005,42(5):1083-1098.

3. Wang Ning. Tourism sociology [M].Tianjin: Nankai University Press,2006 : 145.

4. Zhang Xiaoping. The Theory of "Stage Reality" in Western Tourism Anthropology[J]. Thought Front, 2003, 29(4): 66-6.

5. Tian Meirong, Bao Jigang. Study on the Authenticity Judgment of Tourists on Song and Dance Tourism_- Taking Xishuangbanna Dai Dances as an Example[J]. Journal of Guilin College of Tourism, 2005, 16(1): 12-19.

6. Ren Yujuan. Development of Cultural Tourism Resources Based on the Theory of "Stage Reality"——Taking the Original Ethnic Village as an Example[J]. Journal of Guilin College of Tourism, 2008, 19(1): 129-132..

7. Wang Bo. Evolutionary Game Analysis of Harmonious Development of Tourism Destinations from the Perspective of Stakeholders[J]. Statistics and Decision, 2009 (8): 59-60.

8. Wang Yanping. Research on the Authenticity of Hot Spring Tourism[J]. TOURISM TRIBUNE, 2006, 21(1): 59-63.

9. Xu Wei, Wang Xinxin. The Perception of Tourism Authenticity and Its Relationship with Tourist Satisfaction and Behavioral Intention_- Taking Ancient Village Tourism as an Example[J]. Economic Management, 2011 (4): 111-117.

10. Yang Zhenzhi. Front Desk, Curtain, Backstage_-A New Model of National Culture Protection and Tourism Development[J]. Ethnic Research, 2006 (2): 39-46. 